\title{
Study on the Optimization Strategies for College Physical Education Based on Quality Management
}

\author{
Ziyao Wang \\ Zhuhai College of Jilin University
}

279399748@qq.com

Keywords: College physical education; Teaching; Quality management; Optimization

\begin{abstract}
This paper is going to discuss the concept and basic idea of education quality management and analyze its current development condition and main existing problems based on quality management philosophy. According to this, it will start from the perspectives of education management, resources, process, and quality so as to analyze the basic strategies for college physical education optimization. So, the author is trying tireless efforts to optimize different sectors and perfect its quality control system.
\end{abstract}

\section{Introduction}

Since 1980s, to improve the quality of education is increasingly becoming recognized as a core concept in the field of education all over the world. College education is the last step of cultivating high quality talents. Over the years, the quality of higher education has been the concern of the community. From a survey on college students in China recently, we can see that the comprehensive health level of college students continued to decline, which makes it urgent to strengthen the quality management of college physical education. By combining the characteristics of physical education in colleges, we should study on its optimization strategies in the context of adhering to the philosophy of education quality management, which should be deemed as the key to improve the education quality as well as talents benefits. What's more, it should also be considered as a pivotal issue in college physical education filed.

\section{The Concept of College Physical Education Quality Management and Main Existing Problems}

The concept of education quality management is originated from developed countries in 1980s; however the reform in China legs behind. In 2004, the Ministry of Education lunched a project including education quality and reform. Since 2005, the supervisor Zhou Ji took actions to improve the education quality under the guidance of modern quality management, and vigorously developed education reform and development [1]. After that, the philosophy of education quality management has been deeply developed and implemented. In addition, The CPC central committee and the state council also launched some materials for the purpose of guiding the education development and reform , namely National Medium- and Long-Term Plan for Education Reform and Development

(2010-2020. In this document, it clearly pointed out that the core philosophy of education reform is to improve the education quality and realize quality education. In terms of higher education, it asks us to comprehensively improve the quality of education and talents. All in all, in recent years, people keep talking about education quality based on a glittering array of education practices.

ISO/TC176 was established by International Organization for Standardization in 1979 and ISO launched international standards of Quality-Terms in 1986. After a long time development and perfection, ISO9000 has been successfully created [2]. As an internationally advanced management philosophy, the application of ISO9000 has achieved good effect in the field of enterprise management and education development.

College physical education is a process to have an understanding of the world and cultivate quality under the guidance of teachers and the nature of college physical education is to constantly optimize the process so as to achieve optimal teaching effect. After introducing ISO9000 to college 
physical education, we are able to divide four core sectors (management responsibilities, resource management, production realization, assessment and analysis advancement). During this optimization process, we can have the following four steps: education management responsibilities, education resources management, education service realization and education quality assessment as well s advancement which should be interactive. Based on this, we can come up with an education optimization system so as to guarantee the continual improvement of physical education. The basic process is shown as follows:

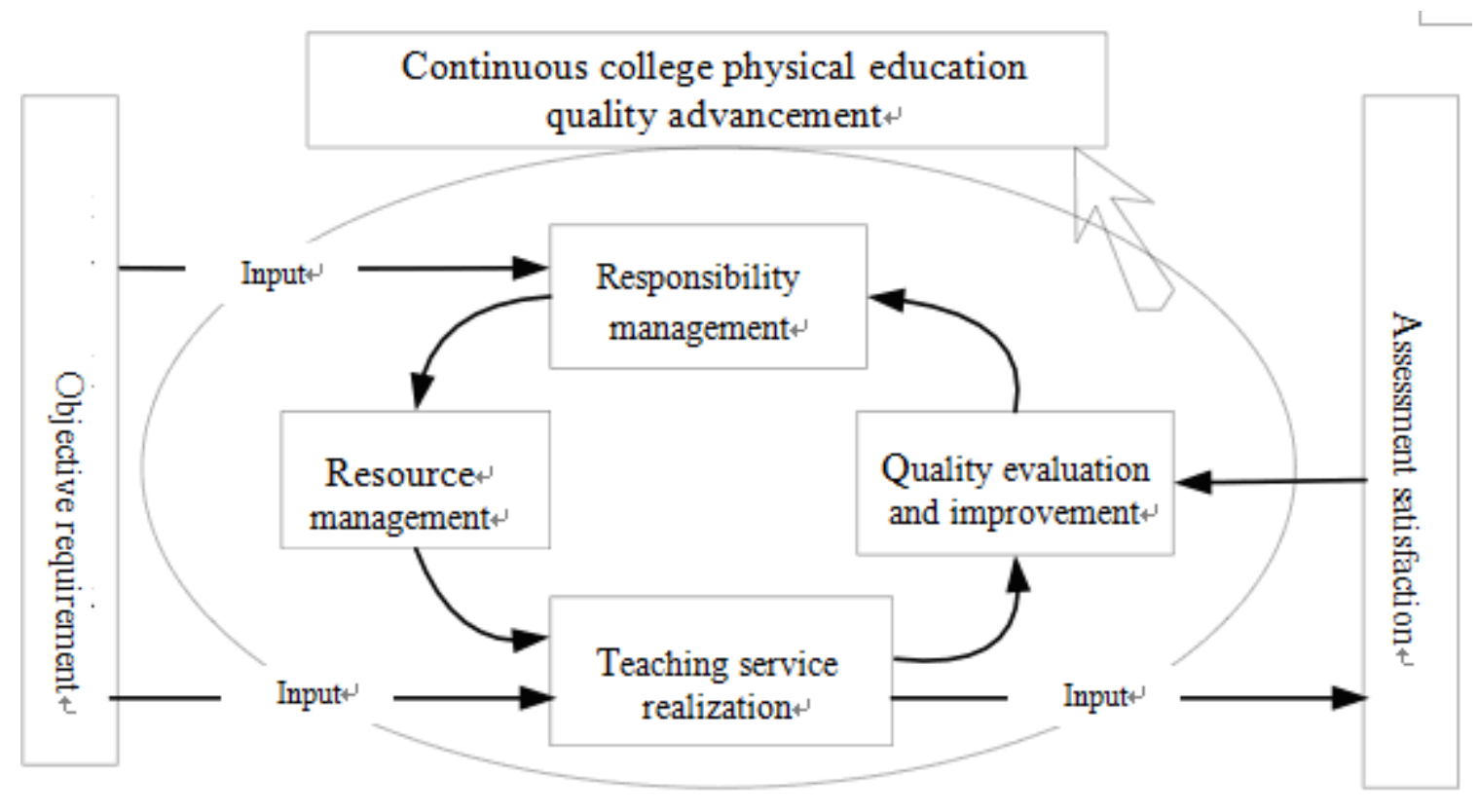

Figure 1. College Physical Education Optimization System Based on Quality Management Philosophy

Based on this quality management framework, and by referring to the philosophy and methods of Total Quality Management, we can establish a new quality management and supervision mechanism from a macro view so as to form a new management mode in terms of college physical education quality.

\section{Main Existing Problems of College Physical Education Quality Management}

Judging from the current situation, the introduction of education quality management in College PE teaching has achieved some results yet there are still problems of innovation shortage from the perspective of implementation section as well as a integral mechanism shortage. Through a systematic analysis, college PE teaching should pay attention to the following aspects concerning quality management control: firstly, the ambiguity of physical education definition and presentation. In recent years, the college physical education reform has developed deeply and physical education objectives have changed from paying attention to skills to physique and to health. In addition, the motor skills, recognition and emotion have all experienced revolutionary reform. Moreover, the teaching objectives are adjusting and updating. As a result, some PE teachers cannot have a general idea of the course philosophy. Typical teaching philosophies include physical education, heath first, skills improvement, and teachers holding different teaching philosophies will vary in terms of goal definition as well as expression.

Secondly, the system of physical education resources system construction is imperfect. Sports venues and sports equipment are important material base to carry put physical education. According to Sports facilities and facilities directory in Colleges launched in 2005 by Ministry of Education, we can see that lots of college stadiums are not equipped with enough facilities, which cannot meet 
the requirement stated in the document and it is difficult to satisfy the needs of college students to carry out physical exercise. As a result, the physical education quality definitely will have a very bad effect and will limit the participation of students. Furthermore, teachers play the main role in physical education yet some of them are not professional and are not equipped with sufficient knowledge as well as ability, which can be also considered as important factors of bad education results.

Thirdly, physical education means lag behind. Judging from the current condition, the education means are traditional: teachers raise a question and stimulate students' passion, teachers demonstrate and students exercise with comments. For a long time, this teaching mode is not wellfocused and it is difficult to implement the core teaching philosophy of developing and being healthy. So, the physical education methods should be optimized.

Fourthly, the quality evaluation system of PE is not comprehensive. In most college physical education, the evaluation is not highly weighed, which is imperfect and not scientific. In addition, it is too simple and put too much emphasis on the result and cannot accurately give feedbacks of education quality.

\section{College Physical Education Optimization Strategies Based on Quality Management Philosophy}

College physical education has its own rules. In order to realize the best result, we have to establish a systematic quality management philosophy and deeply analyze every sector and elements with advanced design. Based on this, we should carry out optimized design and make optimal running mechanism so as to fully play the effect of physical education ${ }^{[3]}$.

To begin with, optimize the education management strategy. The core content of the strategy is to establish an objective system and quality management system. The teaching objective is to guarantee the quality and optimize the management. According to the latest requirement mentioned in P. E. Curriculum Guiding of Colleges All over the Nation, we should generalize the teaching philosophy of being qualified and healthy so as to construct students' healthy status as well as ability to adapt to the society. That is to say, we have to start from the idea of focusing on their future, cultivating their team spirit, and trying to demonstrate the value of physical education. While evaluating the quality of physical education, we adopt the quality management system, asking teachers and students as well as other people involved to adhere to the rules of conduct, which can also be considered as an effective means to guarantee the education quality. By the way, we should construct a healthy and scientific management system so as to carry out scientific and effective management and finally improve the education quality.

Secondly, optimize education resource management. According to the concrete statement of resource management mentioned in ISO9000, we can divide college physical education resource management into human resource management optimization, basic equipment optimization, and teaching environment optimization. The key of human resource management is to establish a teaching faculty with high quality. They are dominant power in physical education, and will play an important role in improving the education quality. Therefore, schools should take every actions to cultivate them. For example, encourage teachers to perfect knowledge structure and professional skill via on-the-job learning and promote outstanding education methods and develop academic atmosphere. The construction of physical education's basic equipment is a main part of teaching environment which supports the smooth implementation of teaching. Concerning the shortage of basic facilities, schools should strengthen the construction and try to satisfy the needs of students. An important content of physical education environment optimization is the construction of campus physical culture. Campus physical culture is a special culture constructed for a long time, which can encourage to create a harmonious environment and stimulate students' passion to participate in physical activities. So, schools should try the utmost to cultivate unique campus physical culture to continually optimize the environment and provide diverse teaching methods. In addition, schools should also encourage teachers to adopt advanced teaching modes to carry out teaching and create a diverse campus atmosphere. 
Thirdly, optimize the education process. Judging from a systematic perspective, college physical education is a complicated process, which is a controllable, interactive and open. During the process, constraint elements include teaching contents, methods, teaching prices and objectives. And one of the key points to improve the quality of physical education is to optimize the teaching process. By referring to standard and basic requirement of products realization and assessment analysis as well as advancement the ISO9000 issued in 2000, the court to optimize the teaching process is to improve the teaching contents and methods while teaching contents should be the most basic part, which directly affect the implementation of teaching goals. In terms of teaching contents, single teaching arrangement can barely satisfy the requirement of modern education if we want to realize the goal of quality education and health first concerning the difference among students. In the teaching process, we should adopt teaching contents in accordance with the characteristics of students with values and properly adjust teaching contents which are highly competitive ${ }^{[4]}$. In the meanwhile, we should also refer to the teaching schedule and students' ability as well as the extracurriculum activities to plan and organize some competitions to satisfy the needs of students at different levels to further create an active education atmosphere. Teaching methods mainly refer to a series of teaching actions in order to complete and implement the teaching outline. As means to complete teaching tasks, its reasonability and optimization problems will contribute a lot to the teaching quality. Teaching means optimization should continually develop new methods in accordance with teaching rules and is able to highlight the main status of students and initiate students' enthusiasm. For example, concerning teaching reality, we should adopt self-learning, team work, different level teaching methods etc. Physical education is practical and participating, so it provides good subject advantages for team work and different level teaching as well as game teaching ${ }^{[5]}$. Judging from the perspective of optimizing college physical education, we should introduce a glittering array of the above teaching methods to improve teaching quality, cultivate their ability and strengthen the quality education to finally create quality education as well as joyful education, which has irreplaceable meaning.

Fourthly, education quality assessment optimization. Education quality assessment is to evaluate the teaching activities and effect based on existed standards ${ }^{[6]}$. Traditional teaching quality assessment mainly paid attention to the feedback of teachers and schools rather than students and the assessment methods are single and most of them are summative evaluation without enough diagnostic evaluations and formative evaluations. The education quality assessment optimization should have diverse evaluation systems and should improve the status of students and encourage students to participate and have self-assessment and ask assessment from others. Furthermore, it is also indispensable to strengthen the function of physical education to improve the body condition and cultivate strong will.

\section{Conclusion}

The formulation of college physical education education should stick to the basic ideas of quality management and starts from the perspectives of education management, resources, process and quality assessment and make them interactive in order to have an optimal condition. Based on this, can we continually improve the education quality control system and improve the education quality steadily and quickly.

\section{References}

[1] Zhou Ji. Comprehensively directing education based on a scientific development concept[R]. A talk on the 2005 annual working conference of Ministry of Education Beijing: Ministry of National Education

[2] Zhao Zhongjian. School management system and ISO9000 standard [M]. Shanghai : East China Normal University Press, 2003 
[3] Shi Haoyue. The application of three standards embraced in one system based education quality management mode in college physical education quality management [D]. Master degree thesis of Beijing Sport University, 2011.01. 